\title{
Longitudinal Study on Metabolic Health in Adults SGA During 5 Years After GH With or Without 2 Years of GnRHa Treatment
}

\author{
Wesley J. Goedegebuure, ${ }^{1,2}$ Manouk van der Steen, ${ }^{2}$ Gerthe F. Kerkhof, ${ }^{1}$ \\ Anita C. S. Hokken-Koelega ${ }^{1,2}$ \\ ${ }^{1}$ Department of Paediatrics, Subdivision Endocrinology, Erasmus University Medical Centre, Rotterdam, \\ The Netherlands; and ${ }^{2}$ Dutch Growth Research Foundation, Rotterdam, The Netherlands
}

ORCiD number: 0000-0002-1990-1090 (W. J. Goedegebuure).

Background: In children born small for gestational age (SGA) with persistent short stature, 2 years of gonadotropin-releasing hormone analogue ( $\mathrm{GnRHa})$, in addition to long-term growth hormone $(\mathrm{GH})$ treatment, can improve adult height. We assessed safety on metabolic and bone health of $\mathrm{GnRHa} / \mathrm{GH}$ treatment during 5 years after cessation of $\mathrm{GH}$.

Methods: A total of 363 young adults born SGA, previously treated with combined GnRHa/ $\mathrm{GH}$ or GH-only, were followed for 5 years after attainment of adult height at GH cessation and 2 and 5 years thereafter. Data at 5 years after GH cessation, at age 21 years, were also compared with 145 age-matched adults born appropriate for gestational age (AGA). Frequently sampled intravenous glucose tolerance (FSIGT) tests were used to assess insulin sensitivity, acute insulin response, and $\beta$-cell function. Body composition and bone mineral density (BMD) was determined by dual-energy $x$-ray absorptiometry (DXA) scans.

Findings: In the $\mathrm{GnRHa} / \mathrm{GH}$ and $\mathrm{GH}$-only groups, fat mass increased during the 5 years after GH cessation, but the changes in FSIGT results, body composition, blood pressure, serum lipid levels, and BMD were similar in both groups. At age 21 years, the GnRHa/GH group had similar fat mass, FSIGT results, blood pressure, serum lipid levels and BMD-total body as the GH-only group and the AGA control group, a higher BMD-lumbar spine and lower lean body mass than the AGA control group.

Interpretation: This study during 5 years after $\mathrm{GH}$ cessation shows that addition of 2 years of $\mathrm{GnRHa}$ treatment to long-term GH treatment of children short in stature born SGA has no unfavorable effects on metabolic and bone health in early adulthood. (J Clin Endocrinol Metab 105: 1-11, 2020)

Clinical trial registration: ISRCTN96883876, ISRCTN65230311 and ISRCTN18062389.

Key Words: SGA, insulin sensitivity, growth hormone, pubertal suppression, metabolic health, GnRHa treatment

n children born small for gestational age (SGA) with persistent short stature, treatment with growth hormone $(\mathrm{GH})$ leads to adult height $(\mathrm{AH})$ improvement (1-3). The Dutch SGA study has shown that

ISSN Print 0021-972X ISSN Online 1945-7197

Printed in USA

C) Endocrine Society 2020. All rights reserved. For permissions, please e-mail: journals. permissions@oup.com

Received 10 January 2020. Accepted 18 May 2020

First Published Online 21 May 2020

Corrected and Typeset 10 June 2020. postponement of puberty with a gonadotropin-releasing hormone analogue (GnRHa) for 2 years at the start of puberty because of an expected $\mathrm{AH}<-2.5$ standard

\footnotetext{
Abbreviations: AGA, appropriate for gestational age; $A H$, adult height; $A I R$, acute insulin response; BMADLS, bone mineral apparent density lumbar spine; BMD, bone mineral density; $\mathrm{BMD}_{1 \mathrm{~S}}, \mathrm{BMD}$ of lumbar spine; $\mathrm{BMD}_{\mathrm{TB}}, \mathrm{BMD}$ of total body; $\mathrm{BMI}$, body mass index; CPP, central precocious puberty; DBP, diastolic blood pressure; DI, disposition index; DXA, dual-energy x-ray absorptiometry; FM, fat mass; FSIGT, frequently sampled intravenous glucose tolerance; GH, growth hormone; GnRHa, gonadotropin-releasing hormone analogue; HDLC, high-density lipoprotein cholesterol; LBM, lean body mass; LDLC, low-density lipoprotein cholesterol; LF, limb fat; SBP, systolic blood pressure; SDS, standard deviation score; SGA, small for gestational age; Sg, glucose effectiveness; Si, insulin sensitivity; TC, total cholesterol; TF, trunk fat; TG, triglyceride.
} 
deviation score (SDS) can improve AH in children born SGA who start GH treatment in early puberty (4).

In patients with central precocious puberty $(\mathrm{CPP})$, a decrease in insulin sensitivity, expressed in the homeostatic model assessment of insulin resistance, was described during GnRHa treatment (5-8). Gain in weight and fat mass during treatment with GnRHa was reported, potentially causing obesity in adulthood (9-13). In studies with patients with CPP, a decrease in bone turnover and bone mineral density (BMD) was observed during GnRHa treatment (12, 14-16). However, studies were performed retrospectively in children with CPP, and most studies evaluated the changes only during GnRHa treatment. Our study group has shown no negative effects of 2 years of GnRHa treatment in addition to GH treatment until AH attainment (17-19). Studies on long-term safety of postponing puberty with GnRHa treatment regarding metabolic health and bone mineralization in young adults born SGA following GH cessation at adult height attainment are lacking.

We performed a longitudinal study during the 5 years after GH cessation in young adults who were treated with $\mathrm{GH}$ until $\mathrm{AH}$, either with or without an additional 2 years of GnRHa after onset of puberty. The primary objective of the study was to assess insulin sensitivity, $\beta$-cell function, body composition, blood pressure, serum lipid levels, and BMD during the 5 years after GH cessation. We hypothesized that postponement of puberty by 2 years of GnRHa treatment in GH-treated young adults born SGA would not negatively influence these outcome measures in early adulthood compared with GH treatment only and would result in a similar metabolic and cardiovascular health profile and BMD in both treatment groups. Our secondary objective was to compare both treatment groups at 5 years after $\mathrm{GH}$ cessation with a healthy young adult cohort. We hypothesized that treatment with either $\mathrm{GnRHa} / \mathrm{GH}$ or $\mathrm{GH}$-only would result in a similar metabolic and cardiovascular health and similar BMD compared with healthy young adults born appropriate for gestational age (AGA).

\section{Method}

\section{Participants}

The study group consisted of 363 young adults born SGA who had participated in 1 of 3 Dutch SGA trials (ISRCTN96883876 [registered January 27, 2006], ISRCTN65230311 [registered September 17, 2006], and ISRCTN18062389 [registered December 20, 2005]). SGA was defined as birth weight or birth length below -2 SDS for gestational age, with a height at the start of GH treatment below -2.5 SDS and no endocrine, metabolic, or chronic disorders. GH treatment was started before puberty or in early puberty and continued until attainment of $\mathrm{AH}$.
Participants received GnRHa treatment for 2 years in addition to $\mathrm{GH}$ treatment ( $\mathrm{n}=112 ; \mathrm{GnRHa} / \mathrm{GH}$ group) or only $\mathrm{GH}$ treatment ( $\mathrm{n}=251 ; \mathrm{GH}$ group). Two years of $\mathrm{GnRHa}$ treatment was prescribed when the expected $\mathrm{AH}$ was less than -2.5 SDS at start of puberty, based on Dutch references (20). A subgroup ( $\mathrm{n}=95)$ was randomly assigned to treatment with either $\mathrm{GH} 1$ or $2 \mathrm{mg} / \mathrm{m}^{2} /$ day $(\sim 0.033$ or $0.067 \mathrm{mg} / \mathrm{kg} / \mathrm{d}$ ) after stratification for sex, pubertal stage, and parental height.

Data at 5 years after GH cessation were compared with those of 145 young adults born AGA (birth length $>-1$ SDS) with a normal stature ( $>-1$ SDS) and aged 18 to 24 years (21, 22). These healthy young adults were recruited from different schools to participate as AGA controls.

The Medical Ethics Committee of the Erasmus University Medical Centre approved the studies. Due to ethical considerations, the Medical Ethics Committee did not allow a randomized untreated SGA group with short stature until adult height. We obtained written informed consent from all participants and from their parents or guardians if they were younger than age 18 years.

\section{Measurements}

At start, every 3 months during $\mathrm{GH}$ treatment and at $\mathrm{AH}$, height was measured to the nearest $0.1 \mathrm{~cm}$ using a Harpenden stadiometer (Holtain, Ltd. Crymmyth, UK). Height was transformed into SDS for sex and chronological age according to Dutch references, using Growth Analyser Research Calculation Tools (Growth Analyser B.V., Rotterdam, The Netherlands). AH SDS was calculated using references for Dutch adults, aged 18 years (20). Weight was measured to the nearest $0.1 \mathrm{~kg}$ (Servo Balance KA-20-150S). Body mass index (BMI) was expressed as SDS adjusted for sex and chronological age, according to Dutch references (20).

\section{Insulin sensitivity and $\beta$-cell function}

Glucose homeostasis was assessed by a frequently sampled intravenous glucose tolerance test (FSIGT) with tolbutamide after an overnight fast (Cutfield WS et al, 1990). Insulin sensitivity $(\mathrm{Si})$, glucose effectiveness $(\mathrm{Sg})$, acute insulin response (AIR), and disposition index (DI) were calculated using Bergman's MINMOD Millennium software (Boston RC et al, 2003). Si quantifies the capacity of insulin to stimulate glucose disposal, and Sg reflects the capacity of glucose to mediate its disposal. AIR is an estimate of insulin secretory capacity, measured as the area under the curve from 0 to 10 minutes and corrected for baseline insulin levels. The DI equals AIR x Si and indicates the $\beta$-cell function.

\section{Body composition and bone mineral density}

Total fat mass (FM), lean body mass (LBM), trunk fat (TF), limb fat (LF), bone mineral density of the total body $\left(\mathrm{BMD}_{\mathrm{TB}}\right)$ and the lumbar spine $\left(\mathrm{BMD}_{\mathrm{LS}}\right)$ were measured by a dual-energy x-ray absorptiometry (DXA) scan on the same machine (Lunar Prodigy, GE Healthcare, Chalfont St Giles, UK). Daily quality assurance was performed. The intra-assay coefficient of variation was $0.41 \%$ to $0.88 \%$ for fat tissue, $1.57 \%$ to $4.49 \%$ for LBM, $0.64 \%$ for $\mathrm{BMD}_{\mathrm{TB}}$, and $1.04 \%$ for the $\mathrm{BMD}_{\mathrm{LS}}(23,24)$. 
In all participants with short stature, true $\mathrm{BMD}_{\mathrm{LS}}$ is underestimated by the areal presentation and should be corrected for bone size by calculating the bone mineral apparent density $\left(\mathrm{BMAD}_{\mathrm{LS}}\right)(25) . \mathrm{BMAD}_{\mathrm{LS}}$ was calculated as follows: $\mathrm{BMAD}_{\mathrm{LS}}=\mathrm{BMD}_{\mathrm{LS}} \times[4 /(\pi \mathrm{x}$ width $)]$, with the width as the mean width of the second to fourth lumbar vertebral body. Because $\mathrm{BMD}_{\mathrm{TB}}$ and $\mathrm{BMAD}_{\mathrm{LS}}$ are dependent on age and gender, SDS were calculated, based on age- and gendermatched reference values from the Dutch population (26, 27).

\section{Blood pressure}

After 10 minutes of rest, diastolic blood pressure (DBP) and systolic blood pressure (SBP) were measured repeatedly during half an hour in supine position, using the nondominant arm with an automated device (Accutorr Plus, Datascope Corp., Montvale NJ, USA). The mean of 7 measurements was taken for analysis, to reflect resting blood pressure. Blood pressure values were adjusted for sex and height. SBP and DBP values were expressed in SDS according to sex- and age-matched reference values (28).

\section{Assays}

Fasting glucose levels were determined on an Architect ci8200 system (Abbott). Fasting insulin levels were measured by IRMA (Medgenix, Biosource Europe) with an intra-assay coefficient of variation of $2.1 \%$ to $1.5 \%$ (6.6-53.3 milligram equivalents/L) and interassay coefficient of variation $6.5 \%$ to 6.1\% (14.4-100.4 milligram equivalents/L).

Total cholesterol (TC) and triglyceride (TG) were measured using an automated enzymatic method with the CHOD-PAP reagent kit and with the GPO-PAP reagent kit, respectively (Roche Diagnostics, Mannheim, Germany). High-density lipoprotein cholesterol (HDLc) was measured using a homogeneous enzymatic colorimetric assay (Roche Diagnostics). Low-density lipoprotein cholesterol (LDLc) was calculated using the Friedewald formula: LDLc $(\mathrm{mmol} / \mathrm{l})=\mathrm{TC}-\mathrm{HDLc}-0.45 \times \mathrm{TG}$.

\section{Data analysis}

Statistical analyses were performed using SPSS version 25. Distribution of variables was determined by the KolmogorovSmirnov test and normal Q-Q-plots. Clinical characteristics are presented as means (SD); the Student $t$ test was used to determine differences between subgroups. Because of a skewed distribution, Si, Sg, AIR, and DI were logtransformed. Longitudinal changes in FSIGT results, body composition, blood pressure, serum lipid levels, and BMD results were analyzed using repeated measurements analysis, with an unstructured covariance matrix. We used sex as a covariate for the initial analysis of longitudinal changes in FSIGT test results, body composition, lipid levels, and BMD results. For longitudinal analyses on blood pressure, we adjusted for sex and age. Analysis of covariance was used for comparisons between the groups at the age of 21 years, with sex as covariate for all variables. Body composition, blood pressure, $\mathrm{BMD}_{\mathrm{TB}}$, and $\mathrm{BMAD}_{\mathrm{LS}}$ were additionally adjusted for height. Results were regarded as statistically significant at $P<0.05$.

\section{Results}

\section{Baseline characteristics}

Table 1 shows the clinical characteristics of all participants at the start of $\mathrm{GH}$ treatment, at $\mathrm{AH}$, and at 21 years of age (5 years after GH cessation). In total, 363 participants (112 GnRHa/GH, $251 \mathrm{GH}$ ) participated in the study. Mean (SD) age at start of GnRHa treatment was 12.1 (1.0) years in boys and 11.2 (1.1) years in girls. In the GnRHa/GH and GH groups, mean age at start of $\mathrm{GH}$ treatment was 9.7 (3.1) versus 7.4 (2.8) years $(P<0.001)$, respectively. At the attainment of $\mathrm{AH}$, mean age in boys was $18.1(0.9)$ versus 17.4 (1.2) years $(P=0.004)$ and $16.4(1.2)$ versus $15.7(0.9)$ years $(P<0.001)$ in girls, in the $\mathrm{GnRHa} / \mathrm{GH}$ and $\mathrm{GH}$ groups, respectively.

At 5 years after GH cessation, mean age was similar in the $\mathrm{GnRHa} / \mathrm{GH}$ and $\mathrm{GH}$ group (22.4 [2.1] vs 21.9 [1.6] years, respectively). The GnRHa/GH group was significantly older than the AGA group (20.8 [2.7] years). The GnRHa/GH group had a different sex distribution (males 33\%) when compared with the GH group (males $56 \%$ ) and AGA group (males $46 \%)(P=0.03$, $P=0.05$, respectively).

\section{GnRHa/GH group versus GH-only group during 5 years after cessation of $\mathrm{GH}$}

Insulin sensitivity and $\beta$-cell function. Table 2 and Figure 1a show the longitudinal changes in $\mathrm{Si}, \mathrm{Sg}$, AIR, and DI after GH cessation in the GnRHa/GH and GH groups. Changes in $\mathrm{Si}, \mathrm{Sg}$, AIR, and DI were similar in the $\mathrm{GnRHa} / \mathrm{GH}$ and $\mathrm{GH}$ groups during the 5 years after GH cessation $(P=0.39, P=0.07, P=0.79, P=0.92$, respectively). Additional adjustment for age did not change these results.

In the $\mathrm{GnRHa} / \mathrm{GH}$ group, $\mathrm{Si}$ increased significantly during the first 2 years after $\mathrm{GH}$ cessation, while the Sg and AIR decreased significantly (all $P<0.001$ ). In the following 3 years, Si, Sg, and AIR remained similar. DI remained similar during the 5 years after GH cessation. Similarly, in the GH group, during the first 2 years after GH cessation. Si increased and both Sg and AIR decreased (all $P<0.001$ ). In the following 3 years, Si, $\mathrm{Sg}$, and AIR remained similar. DI also remained similar during the 5 -year follow-up period.

At 5 years after GH cessation, the GnRHa/GH group had a similar Si, AIR, and DI and a significantly lower $\mathrm{Sg}(P=0.049)$ than the GH group (Table 3). None of the participants in the $\mathrm{GnRHa} / \mathrm{GH}$ group and $\mathrm{GH}$ group had glucose intolerance or developed type 2 diabetes up to 5 years after GH cessation. 


\section{Table 1. Baseline characteristics}

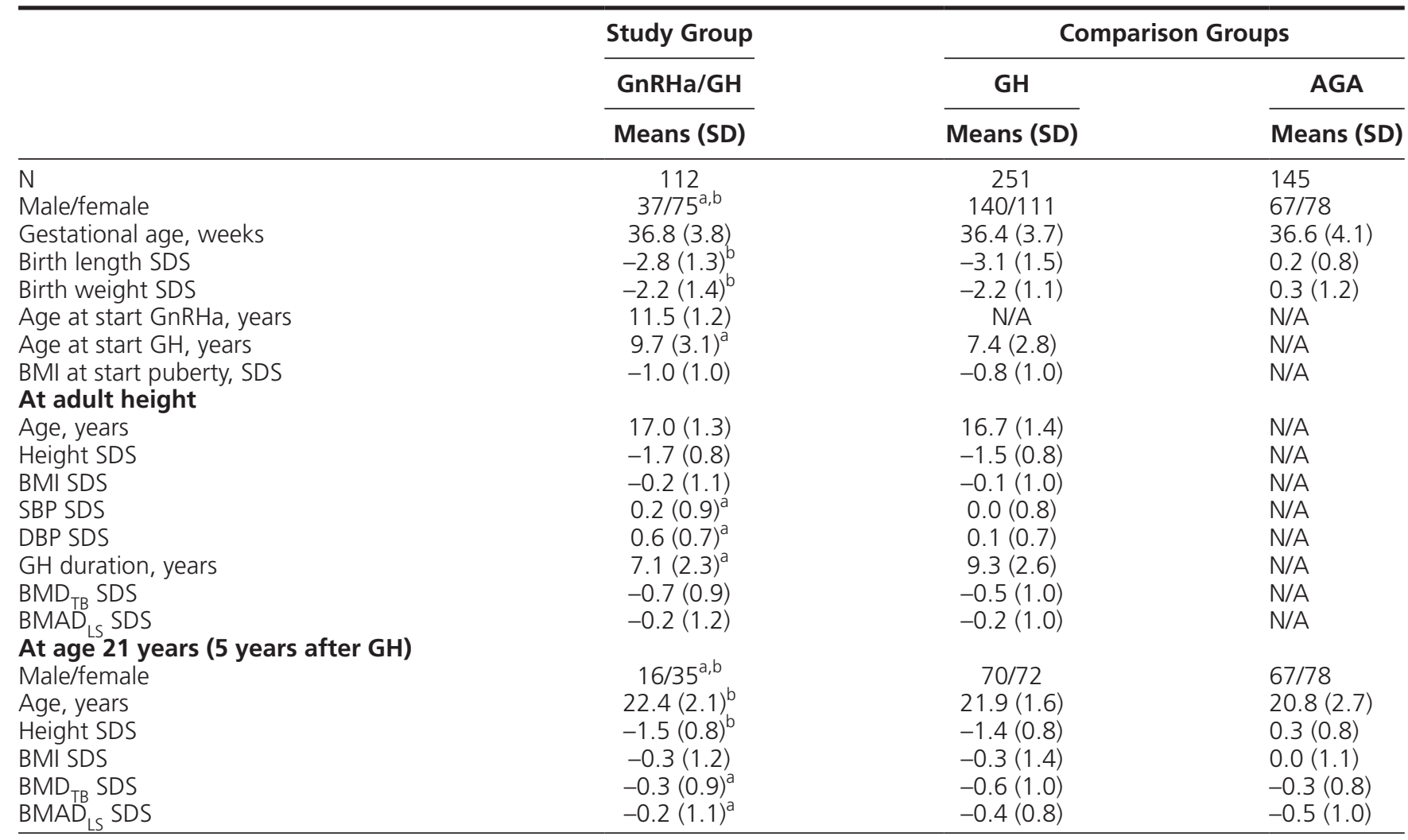

Values are presented as means (SD).

Abbreviations: $A G A, B M A D_{L S}$, bone mineral apparent density lower spine; $B_{M D_{T B}}, B M D$ of total body; $B M l$, body mass index; $D B P$, diastolic blood pressure $\mathrm{GH}$, growth hormone; GnRHa, gonadotropin-releasing hormone agonist; N/A, not available; SBP, systolic blood pressure; SD, standard deviation; SDS, SD score.

${ }^{\mathrm{a}} \mathrm{P}<0.05$ compared with $\mathrm{GH} .{ }^{\mathrm{b}} \mathrm{P}<0.05$ compared with $\mathrm{AGA}$.

Body composition. Table 2 and Figure $1 \mathrm{~b}$ show the longitudinal changes in body composition after $\mathrm{GH}$ cessation in the GnRHa/GH and GH groups, measured by DXA-scan. Changes in FM, LBM, TF, and LF were similar in the $\mathrm{GnRHa} / \mathrm{GH}$ group and $\mathrm{GH}$ group during the 5 -year follow-up period $(P=0.26, P=0.08$, $P=0.24, P=0.10$, respectively). Additional adjustment for age did not change the results.

In the GnRHa/GH group, FM, LF, and TF increased consistently and significantly during the 5 years after GH cessation (all $P<0.001$ ), whereas LBM remained similar during this follow-up period. Also, in the $\mathrm{GH}$ group, FM, LF, and TF increased consistently and significantly, while LBM remained similar during this 5 -year follow-up period.

At 5 years after GH cessation, FM, LBM, TF, and LF were similar in the $\mathrm{GnRHa} / \mathrm{GH}$ and $\mathrm{GH}$ groups (Table 3). Mean (SD) BMI SDS was -0.3 (1.2) in the $\mathrm{GnRHa} / \mathrm{GH}$ group, which was similar in the GH group $(-0.3(1.4) ; P=0.90)$.

Blood pressure. Table 2 and Figure 2 a show the longitudinal changes in SBP and DBP in the GnRHa/GH and GH groups. The GnRHa/GH group had higher SBP and DBP values at $\mathrm{GH}$ cessation, but changes in SBP and DBP during the 5 years after $\mathrm{GH}$ cessation were similar in both groups $(P=0.84, P=0.43$, respectively).

In the GnRHa/GH group, SBP and DBP remained similar and within normal range (from 115.6 to $116.4 \mathrm{mmHg} ; P=0.06$ and from 68.9 to $70.0 \mathrm{mmHg}$; $P=0.27$, respectively) during 5 years after GH cessation. In the GH group, both SBP and DBP remained well within the normal range but increased significantly during the 5-year follow-up period (from 112.6 to $116.0 \mathrm{mmHg}$ and from 64.0 to $66.3 \mathrm{mmHg}$, respectively, both $P<0.001$ ).

At 5 years after GH cessation, SBP and DBP were still well within the normal range in both groups. The GnRHa/GH group had similar SBP $(119.5 \mathrm{mmHg})$ and higher DBP $(71.0 \mathrm{mmHg})$ when compared with the GH group (117.6 and $67.7 \mathrm{mmHg} ; P=0.40$ and $P=0.01$, respectively) (Table 3 ).

Serum lipid levels. Table 2 and Figure $2 b$ show the longitudinal changes in serum lipid levels in the GnRHa/ $\mathrm{GH}$ and GH groups. Changes in TC, HDLc, LDLc, and 
Table 2. Longitudinal data during 5 years after GH cessation

\begin{tabular}{|c|c|c|c|c|c|c|}
\hline Outcome & Study Moment & \multicolumn{2}{|c|}{ GnRHa/GH } & \multicolumn{2}{|l|}{ GH } & $P$ Value \\
\hline \multirow{2}{*}{$\begin{array}{l}\text { Insulin sensitivity } \\
(\mathrm{mU} / \mathrm{L})\end{array}$} & $\mathrm{AH}$ & 4.963 & $4.20-5.72$ & 5.008 & $4.49-5.52$ & \multirow[t]{2}{*}{0.391} \\
\hline & 5 yrs after $\mathrm{AH}$ & 7.471 & $5.88-9.06$ & 7.902 & $6.90-8.90$ & \\
\hline \multirow{2}{*}{$\begin{array}{l}\text { Glucose effectiveness } \\
(\mathrm{mg} / \mathrm{dL})\end{array}$} & $\mathrm{AH}$ & 0.019 & $0.018-0.021$ & 0.018 & $0.017-0.019$ & \multirow[t]{2}{*}{0.072} \\
\hline & 2 yrs after $A H$ & 0.021 & $0.019-0.022$ & 0.021 & $0.020-0.023$ & \\
\hline \multirow{2}{*}{$\begin{array}{l}\text { Acute insulin response } \\
(\mathrm{mU} / \mathrm{L})\end{array}$} & 2 yrs after $A H$ & 639.0 & $537.9-740.1$ & 570.1 & $495.3-644.9$ & \multirow{2}{*}{0.794} \\
\hline & 5 yrs after $\mathrm{AH}$ & 587.7 & $473.4-702.1$ & 555.3 & $480.3-630.2$ & \\
\hline \multirow[t]{3}{*}{ Disposition index } & $\mathrm{AH}$ & 2815.1 & $2404-3227$ & 2880.6 & $2604-3157$ & \multirow[t]{3}{*}{0.921} \\
\hline & 2 yrs after $A H$ & 3131.3 & $2589-3673$ & 3574.6 & $3146-4002$ & \\
\hline & 5 yrs after $\mathrm{AH}$ & 3248.3 & $2516-3980$ & 3159.4 & $2694-3625$ & \\
\hline Fat mass (in kg) & $\mathrm{AH}$ & 12.80 & $11.7-13.9$ & 10.44 & $9.7-11.2$ & 0.256 \\
\hline Lean body mass (in kg) & 5 yrs after $\mathrm{AH}$ & 39.66 & $38.0-41.3$ & 42.38 & $41.3-43.5$ & 0.075 \\
\hline \multirow[t]{3}{*}{$\mathrm{SBP}(\mathrm{mmHg})$} & $\mathrm{AH}$ & 114.94 & $112.9-116.9$ & 112.85 & $111.5-114.2$ & \multirow[t]{3}{*}{0.837} \\
\hline & 2 yrs after $A H$ & 116.01 & $114.0-118.1$ & 113.90 & $112.5-115.3$ & \\
\hline & 5 yrs after $\mathrm{AH}$ & 117.39 & $114.8-119.9$ & 116.09 & $114.5-117.7$ & \\
\hline \multirow[t]{3}{*}{$\mathrm{DBP}(\mathrm{mmHg})$} & $\mathrm{AH}$ & 68.87 & $67.4-70.4$ & 64.03 & $63.0-65.1$ & \multirow[t]{3}{*}{0.426} \\
\hline & 2 yrs after $A H$ & 69.87 & $68.4-71.4$ & 65.07 & $64.1-66.1$ & \\
\hline & 5 yrs after $\mathrm{AH}$ & 69.77 & $67.9-71.6$ & 66.30 & $65.1-67.5$ & \\
\hline \multirow{3}{*}{$\mathrm{TC}(\mathrm{mmol} / \mathrm{L})$} & $\mathrm{AH}$ & 4.00 & $3.9-4.1$ & 3.95 & $3.9-4.0$ & \multirow[t]{3}{*}{0.391} \\
\hline & 2 yrs after $A H$ & 4.29 & $4.1-4.5$ & 4.13 & $4.0-4.3$ & \\
\hline & 5 yrs after $\mathrm{AH}$ & 4.46 & $4.3-4.7$ & 4.30 & $4.2-4.4$ & \\
\hline \multirow[t]{2}{*}{$\mathrm{HDLC}(\mathrm{mmol} / \mathrm{L})$} & $\mathrm{AH}$ & 1.45 & $1.4-1.5$ & 1.42 & $1.4-1.5$ & 0.724 \\
\hline & 2 yrs after $A H$ & 1.47 & $1.4-1.5$ & 1.44 & $1.4-1.5$ & \\
\hline$(S D S)^{T B}$ & 2 yrs after $A H$ & -0.54 & -0.76 to -0.32 & -0.61 & -0.88 to -0.34 & \\
\hline & 5 yrs after $\mathrm{AH}$ & -0.47 & -0.72 to -0.22 & -0.57 & -0.88 to -0.27 & 0.182 \\
\hline $\mathrm{BMAD}_{\perp \mathrm{S}}$ & $\mathrm{AH}$ & -0.21 & -0.42 to -0.00 & -0.18 & -0.38 to 0.02 & \\
\hline (SDS) & 2 yrs after $\mathrm{AH}$ & -0.23 & -0.43 to -0.02 & -0.39 & -0.58 to -0.20 & \\
\hline & 5 yrs after $\mathrm{AH}$ & -0.26 & -0.49 to -0.03 & -0.36 & -0.58 to -0.14 & 0.081 \\
\hline
\end{tabular}

Results of repeated measurements analysis, presented as estimated marginal means with $95 \% \mathrm{Cl}$, and $P$ values for repeated measurements in the zero-year to 5-year follow-up. All variables were corrected for sex; blood pressure was additionally adjusted for age.

$P$ value: difference in change between $\mathrm{GnRHa} / \mathrm{GH}$ and $\mathrm{GH}$ group in outcome variable during 5 years after cessation. Abbreviations: AH, adult height; $B M A D_{L S}$, bone mineral apparent density lumbar spine; $B M D$, bone mineral density; $\mathrm{BMD}_{\mathrm{TB}}, \mathrm{BMD}$ of total body; $\mathrm{Cl}$, confidence interval; $\mathrm{DBP}$, diastolic blood pressure; EMM, estimated marginal mean; GH, growth hormone; GnRHa, gonadotropin-releasing hormone agonist; HDLc, high-density lipoprotein cholesterol; LDLc, low-density lipoprotein cholesterol; SBP, systolic blood pressure; SDS, standard deviation score; TC, total cholesterol; TG, triglyceride; yrs, years.

TG during the 5 years after GH cessation were similar in both groups $(P=0.39, P=0.71, P=0.40, P=0.18$, respectively). Additional adjustment for age and FM did not change these results.

In the GnRHa/GH group, TC, HDLc, and LDLc increased significantly $(P<0.001, P=0.008, P<0.001$, respectively), while TG remained similar during the 5 years after $\mathrm{GH}$ cessation $(P=0.50)$. In the $\mathrm{GH}$ group, TC and LDLc also increased significantly
$(P<0.001)$, but HDLc and TG remained similar during this 5 -year follow-up period $(P=0.26$, $P=0.98$, respectively).

At 5 years after $\mathrm{GH}$ cessation, the $\mathrm{GnRHa} / \mathrm{GH}$ and GH groups had similar serum lipid levels (TC: $P=0.46$; HDLc: $P=0.38$; LDLc: $P=0.36$; TG: $P=0.10)$.

BMD. Table 2 and Fig. 2c show the longitudinal changes in $\mathrm{BMD}_{\mathrm{TB}} \mathrm{SDS}$ and $\mathrm{BMAD}_{\mathrm{LS}} \mathrm{SDS}$ in the 
1 a.

Insulin sensitivity

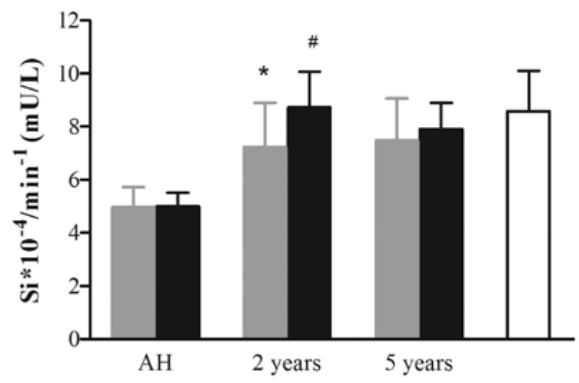

$1 b$.

Fat mass

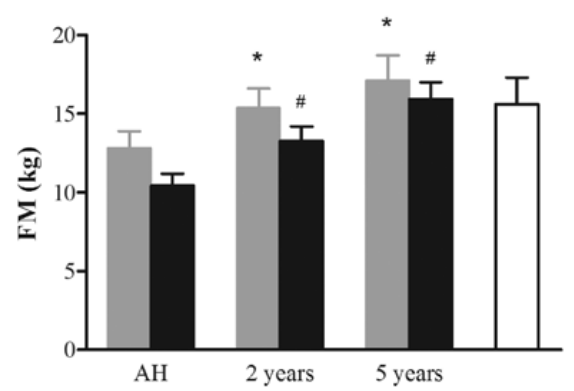

Trunk fat

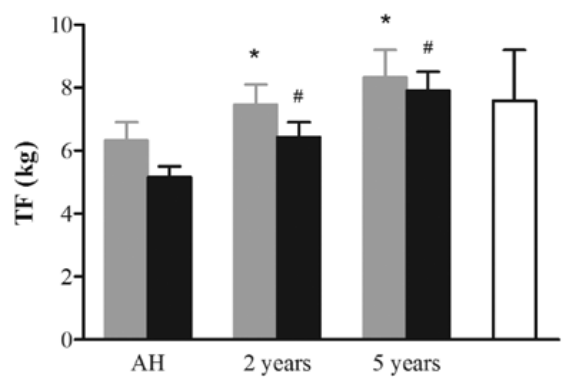

Beta-cell function

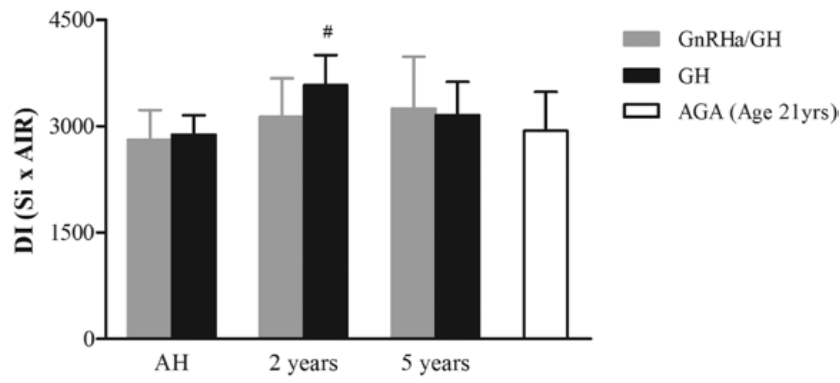

Lean body mass

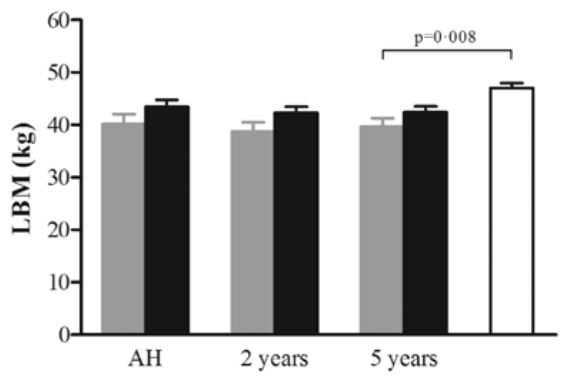

Limb fat

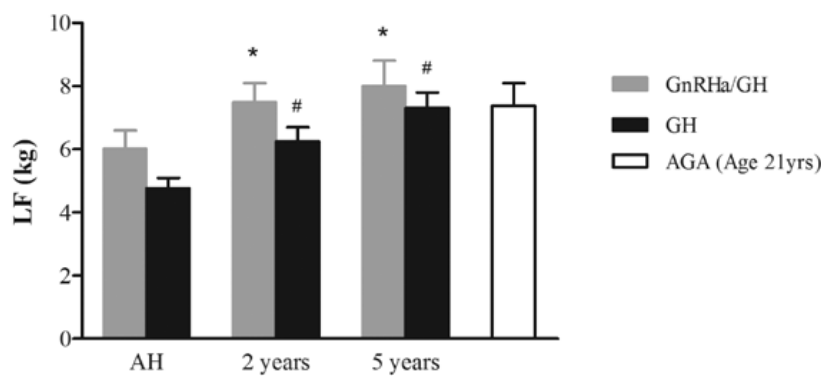

Figure 1. Longitudinal changes during 5 years after GH cessation in FSIGT results (a) and body composition (b). Data are expressed as estimated marginal means with the upper limit of the $95 \%$ confidence interval, adjusted for sex. Body composition was additionally adjusted for height. $P$ values for the comparison between groups at 5 years after $\mathrm{GH}$ cessation were depicted if $P$ values $<0.05$. Abbreviations: AGA, appropriate for gestational age; AH, adult height; AIR, acute insulin response; DI, disposition index; FM, fat mass; GH, growth hormone; GnRHa, gonadotropinreleasing hormone agonist; LBM, lean body mass; LF, limb fat; SI, insulin sensitivity; TF, trunk fat; yrs, years.

* $P$ value $<0.05$ compared with previous visit in $\mathrm{GnRHa} / \mathrm{GH}$-treated young adults.

\# $P$ value $<0.05$ compared with previous visit in $\mathrm{GH}$-treated young adults.

$\mathrm{GnRHa} / \mathrm{GH}$ and $\mathrm{GH}$ groups. Changes in $\mathrm{BMD}_{\mathrm{TB}} \mathrm{SDS}$ and $\mathrm{BMAD}_{\mathrm{LS}}$ SDS during the 5 years after $\mathrm{GH}$ cessation were similar in both groups $(P=0.182$ and $P=0.081$, respectively).

In the $\mathrm{GnRHa} / \mathrm{GH}$ group, $\mathrm{BMD}_{\mathrm{TB}} \mathrm{SDS}$ increased significantly $(P=0.009)$ and $\mathrm{BMAD}_{\mathrm{LS}}$ remained similar $(P=0.89)$. In the $\mathrm{GH}$ group, both the $\mathrm{BMD}_{\mathrm{TB}}$ and $\mathrm{BMAD}_{\mathrm{LS}}$ remained similar $(P=0.33$ and $P=0.85$, respectively) during the 5 years after $\mathrm{GH}$ cessation.

At 5 years after $\mathrm{GH}$ cessation, the $\mathrm{GnRHa} / \mathrm{GH}$ group had a similar $\mathrm{BMD}_{\mathrm{TB}}$ and $\mathrm{BMAD}_{\mathrm{LS}}$, compared with the
GH group $(-0.29$ vs -0.60 SDS; $P=0.170$ and -0.26 vs $-0.44 ; P=0.053$, respectively).

\section{GnRHa/GH group versus AGA group at 21 years of age}

Insulin sensitivity and $\beta$-cell function measured by FSIGT. The GnRHa/GH group had a similar Si, Sg, AIR, and DI as the AGA group (Table 3, Fig. 1a). None of the participants of the $\mathrm{GnRHa} / \mathrm{GH}, \mathrm{GH}$, or AGA groups had diabetes mellitus at 21 years of age. 
Table 3. Comparison between the groups at age 21 years

\begin{tabular}{|c|c|c|c|c|c|}
\hline & GnRHa/GH & GH & & AGA & \\
\hline & EMM $(95 \%$ Cl) & EMM $(95 \% \mathrm{Cl})$ & $P$ Value ${ }^{a}$ & EMM $(95 \% \mathrm{Cl})$ & $P$ Value $^{b}$ \\
\hline \multicolumn{6}{|l|}{ Glucose metabolism } \\
\hline Glucose effectiveness & $0.019(0.017-0.022)$ & $0.021(0.020-0.023)$ & 0.049 & $0.018(0.016-0.020)$ & 0.888 \\
\hline Insulin sensitivity & $8.03(5.9-10.1)$ & $8.01(6.7-9.3)$ & 0.228 & $8.585(7.1-10.1)$ & 0.766 \\
\hline Acute insulin response & $509.6(386.3-633.1)$ & $572.0(497.1-646.6)$ & 0.373 & $441.3(350.4-532.1)$ & 0.885 \\
\hline Disposition index ${ }^{\mathrm{C}}$ & $3171.7(2428-3915)$ & $3217.8(2768-3667)$ & 0.791 & $2935(2388-3483)$ & 0.887 \\
\hline \multicolumn{6}{|l|}{ Body composition } \\
\hline Fat mass $(\mathrm{kg})$ & $16.36(14.0-18.7)$ & $16.76(15.3-18.3)$ & 0.756 & $15.61(14.0-17.3)$ & 0.649 \\
\hline Lean body mass $(\mathrm{kg})$ & $44.89(43.7-46.1)$ & $44.18(43.42-44.94)$ & 0.283 & $47.05(46.2-47.9)$ & 0.008 \\
\hline Trunk fat (kg) & $8.19(6.9-9.5)$ & $8.33(7.5-9.2)$ & 0.851 & $7.59(6.5-9.2)$ & 0.494 \\
\hline Limb fat $(\mathrm{kg})$ & $7.60(6.5-8.7)$ & $7.70(7.0-8.4)$ & 0.860 & $7.38(6.6-8.1)$ & 0.771 \\
\hline \multicolumn{6}{|l|}{ Blood pressure } \\
\hline Systolic (mmHg) & $119.5(116-122)$ & $117.6(116-120)$ & 0.259 & $116.6(11-119)$ & 0.167 \\
\hline Diastolic (mmHg) & $71.0(69-73)$ & $67.7(66-71)$ & 0.012 & $69.0(67-71)$ & 0.226 \\
\hline \multicolumn{6}{|l|}{ Serum lipid levels } \\
\hline $\mathrm{TC}(\mathrm{mmol} / \mathrm{L})$ & $4.40(4.2-4.6)$ & $4.30(4.2-4.6)$ & 0.460 & $4.39(4.3-4.5)$ & 0.977 \\
\hline $\mathrm{HDLC}(\mathrm{mmol} / \mathrm{L})$ & $1.53(1.4-1.6)$ & $1.46(1.4-1.6)$ & 0.382 & $1.43(1.4-1.5)$ & 0.117 \\
\hline $\mathrm{LDLc}(\mathrm{mmol} / \mathrm{L})$ & $2.70(2.5-2.9)$ & $2.59(2.5-2.7)$ & 0.357 & $2.56(2.4-2.7)$ & 0.257 \\
\hline $\mathrm{TG}(\mathrm{mmol} / \mathrm{L})$ & $0.91(0.8-1.0)$ & $1.03(1.0-1.2)$ & 0.101 & $0.98(0.9-1.1)$ & 0.356 \\
\hline \multicolumn{6}{|l|}{ Bone mineral density } \\
\hline $\mathrm{BMD}_{\mathrm{TR}}(\mathrm{SDS})$ & $-0.29(-0.7$ to 0.1$)$ & $-0.60(-0.8$ to -0.4$)$ & 0.170 & $-0.41(-0.6$ to -0.2$)$ & 0.595 \\
\hline $\begin{array}{l}B_{1 B} \\
B_{L S} \text { (SDS) }\end{array}$ & $-0.26(-0.5$ to 0.0$)$ & $-0.44(-0.6$ to -0.3$)$ & 0.053 & $-0.58(-0.8$ to -0.4$)$ & 0.009 \\
\hline
\end{tabular}

Results of the ANCOVA analysis between GnRHa/GH, GH, and AGA at 21 years of age. All variables were corrected for sex; body composition and bone mineral density were additionally adjusted for height; blood pressure was additionally adjusted for height. Abbreviations: ANCOVA, analysis of covariance; $A G A$, appropriate for gestational age; $B_{M A D}$, bone mineral apparent density lumbar spine; $\mathrm{BMD}_{\mathrm{TB}}, \mathrm{BMD}$ of total body; $C \mathrm{Cl}_{\mathrm{L}}$ confidence interval; EMM, estimated marginal mean; GH, growth hormone; GnRHa, gonadotropin-releasing hormone agonist; HDLc, high-density lipoprotein cholesterol; LDLc, low-density lipoprotein cholesterol; SDS, standard deviation score; TC, total cholesterol; TG, triglyceride.

${ }^{a} P$ value for the comparison between $\mathrm{GnRHa} / \mathrm{GH}$-treated and $\mathrm{GH}$-treated young adults born SGA.

${ }^{b} P$ value for the comparison between $\mathrm{GnRHa} / \mathrm{GH}$-treated young adults born SGA and young adults born AGA

${ }^{\mathrm{c}} \mathrm{A}$ measure of $\beta$-cell function, calculated as insulin sensitivity $\times$ acute insulin response.

Body composition. FM, TF, and LF were similar in the GnRHa/GH and AGA groups, but LBM was lower in the GnRHa/GH group $(P=0.002)$ (Table 3, Fig. $1 b)$. The GnRHa/GH group had a similar mean BMI SDS as the AGA group (-0.3 [1.2] vs 0.0 [1.1]; $P=0.08)$. Only $1(0.8 \%)$ participant of the $\mathrm{GnRHa} / \mathrm{GH}$ group had a BMI above 2 SDS, which did not significantly differ from the GH group (7 participants, $2.5 \%$ ) and the AGA group (4 participants, $2.8 \%$ ).

Blood pressure. The GH/GnRHa group had similar SBP and DBP compared with the AGA group $(P=0.17$, $P=0.23$, respectively) (Table 3 , Fig. $2 \mathrm{a}$ ). The number of participants with a high SBP (above $140 \mathrm{mmHg}$ ) or high DBP (above $90 \mathrm{mmHg}$ ) at age 21 years did not differ between the $\mathrm{GnRHa} / \mathrm{GH}, \mathrm{GH}$, and AGA groups. High SBP: GnRHa/GH: 2 (3.9\%); GH: 5 (3.5\%); AGA: $4(2.8 \%)$ and high DBP: GnRHa/GH: 2 (3.9\%); GH: 1 $(0.7 \%)$; and AGA: $0(0 \%)$.

Serum lipid levels. The GnRHa/GH group had similar serum lipid levels as the AGA group (Table 3, Fig. 2b). Additional adjustment for body fat did not change the results.
BMD. The GnRHa/GH group had a similar $\mathrm{BMD}_{\mathrm{TB}}$ SDS $(P=0.60)$ and a higher $\mathrm{BMAD}_{\mathrm{LS}}$ compared with the AGA group $(-0.26$ vs -0.58 SDS; $P=0.009)$ (Table 3).

\section{Effect of treatment with 2 versus $1 \mathrm{mg} \mathrm{GH} / \mathrm{m}^{2} /$ day at 21 years of age}

A subgroup of participants $(\mathrm{n}=95)$ was randomly assigned to receive either 2 or $1 \mathrm{mg} \mathrm{GH} / \mathrm{m}^{2} /$ day from start of puberty until GH cessation (data not shown). At 5 years after GH cessation, those treated with $2 \mathrm{mg}$ $\mathrm{GH} / \mathrm{m}^{2} /$ day had a significantly higher LBM $(P=0.04)$ than those treated with $\mathrm{GH} 1 \mathrm{mg} \mathrm{GH} / \mathrm{m}^{2} /$ day. In the participants who had received $2 \mathrm{mg} \mathrm{GH} / \mathrm{m}^{2} /$ day, FM and TF were lower, and LBM was higher compared with those who were treated with $1 \mathrm{mg} \mathrm{GH} / \mathrm{m}^{2} /$ day $(P=0.06, P=0.09, P=0.07$, respectively). FSIGT results, LF, blood pressure, serum lipid levels, and BMD were similar in both GH-dose groups.

\section{Discussion}

This longitudinal study during the 5 years after discontinuation of $\mathrm{GH}$ treatment is currently the longest 
2a.

Systolic blood pressure

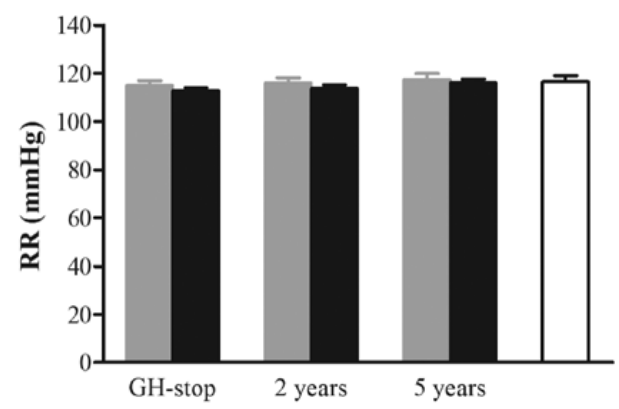

2 b.

Total cholesterol

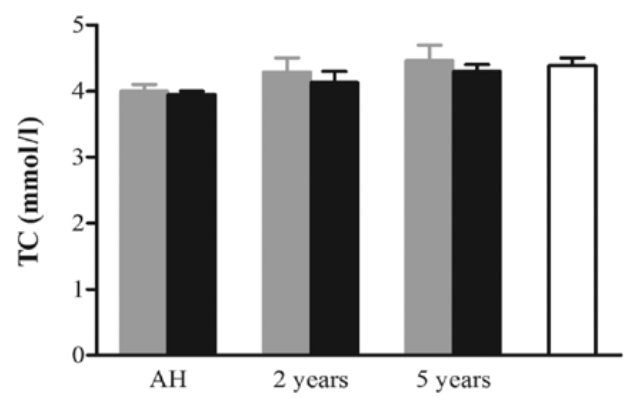

LDL cholesterol

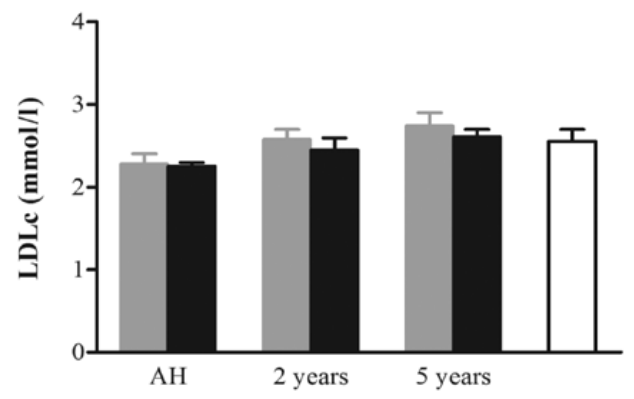

2c.

Bone mineral density

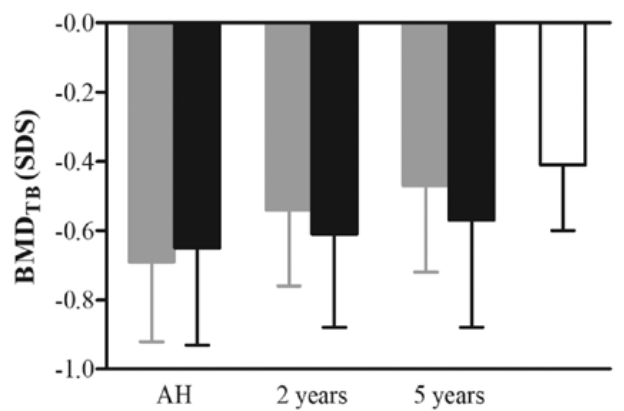

Diastolic blood pressure

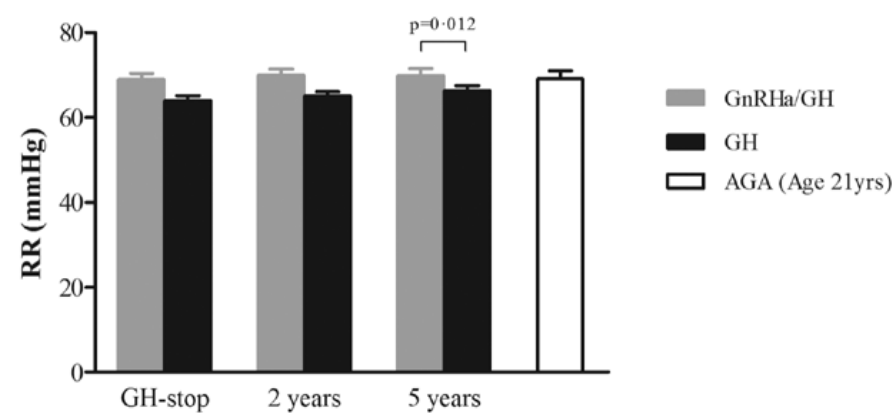

HDL cholesterol

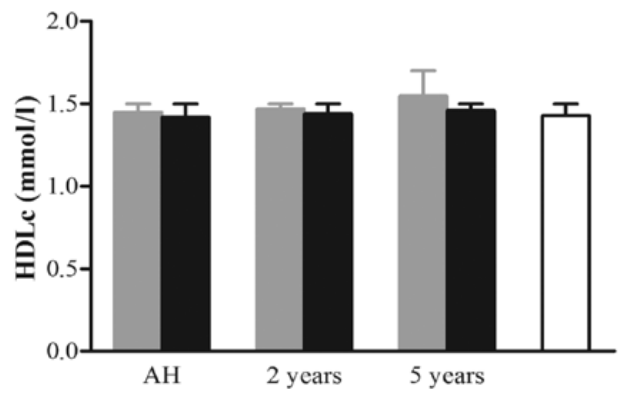

Triglycerides

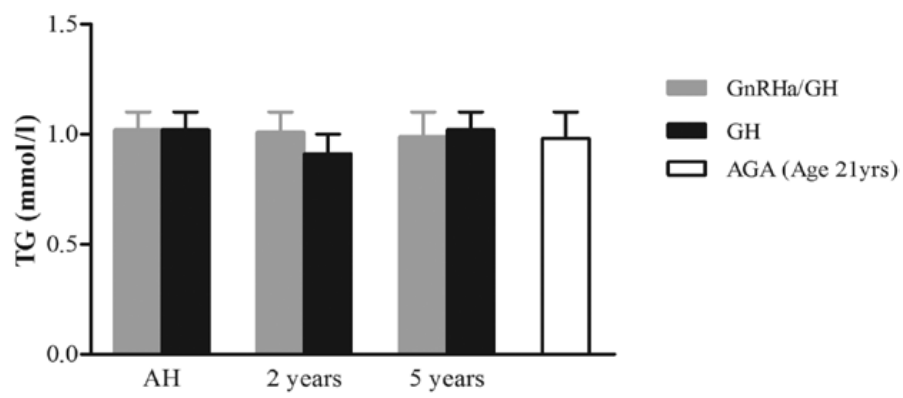

Bone mineral apparent density

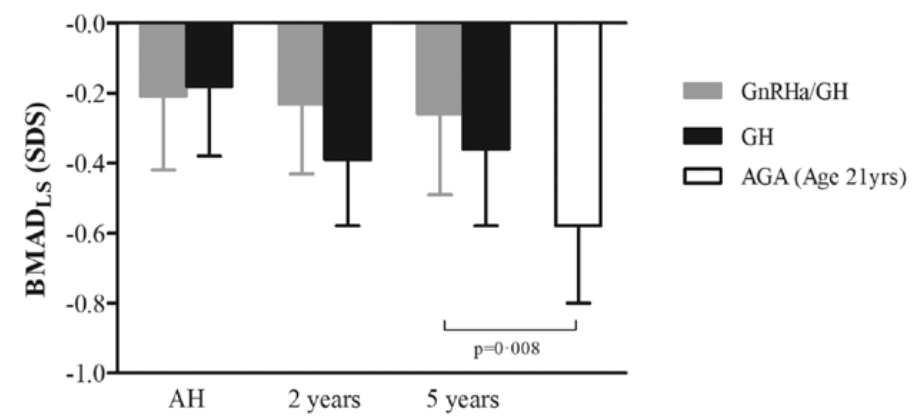

Figure 2. Longitudinal changes during 5 years after GH cessation in blood pressure (a), serum lipid levels (b), and bone mineral density (c). Data are expressed as estimated marginal means with the upper limit of the 95\% confidence interval, adjusted for sex. $P$ values for the comparison between groups at 5 years after $\mathrm{GH}$ cessation were depicted if $P$ values $<0.05$. Abbreviations: AGA, appropriate for gestational age; $\mathrm{AH}$, adult height; $\mathrm{BMD}_{\mathrm{TB}}$, bone mineral density of the total body; $\mathrm{BMD}_{\mathrm{LS}}$, bone mineral density of the lumbar spine; GH, growth hormone; GnRHa, gonadotropin-releasing hormone agonist; HDL, high-density lipoprotein; LDL, low-density lipoprotein; RR, Riva-Rocci; SDS, standard deviation score; TC, total cholesterol; TG, triglyceride; yrs, years. 
follow-up study in a large group of young adults born SGA who were treated during childhood with 2 years of GnRHa in addition to GH treatment. We show that 2 years of GnRHa treatment in addition to GH treatment does not change the metabolic health profile in terms of insulin sensitivity, $\beta$-cell function, body composition, blood pressure, serum lipid levels, and BMD. At 21 years of age, the GnRHa/GH group had a similar metabolic health profile and $\mathrm{BMD}_{\mathrm{TB}}$ as the $\mathrm{GH}$-only and AGA groups and a higher $\mathrm{BMD}_{\mathrm{LS}}$ compared with the AGA group.

Our study shows that insulin sensitivity and $\beta$-cell function increased similarly during the first 2 years after GH cessation in both GnRHa-treated young adults and those treated with GH only. We also found that the GnRHa/GH group had similar FSIGT results as healthy young adults born AGA. A cross-sectional retrospective study by Lazar et al also showed no metabolic derangements in GnRHa-treated female adults with CPP aged 30 to 50 years (10). Several studies during GnRHa treatment in children with CPP showed lower insulin sensitivity, expressed as the homeostatic model assessment of insulin resistance (5-8). This might be explained by the difference in population as early puberty also increases the risk of diabetes (17). Our study shows that the addition of 2 years of GnRHa treatment during childhood does not influence insulin sensitivity and $\beta$-cell function in young adults born SGA.

We found no higher prevalence of obesity and a similar fat mass in the GnRHa/GH-treated young adults compared with young adults treated with GH-only and healthy young adults born AGA. Several studies in children with CPP described an increase in weight and BMI during GnRHa treatment, which could negatively influence metabolic health and cause a higher prevalence of obesity in adulthood (9-13). However, studies in children born SGA and children with CPP have also shown that an increase in BMI during GnRHa treatment did not lead to a higher rate of obesity at $\mathrm{AH}$ (10, 17, 29). Furthermore, earlier pubertal timing has been associated with higher BMI and a higher prevalence of diabetes and metabolic disease, thus it is questionable whether the described alterations in metabolic health are due to CPP rather than GnRHa treatment. Earlier pubertal timing has been associated with higher BMI and a higher prevalence of diabetes and metabolic disease (30). Our results show that 2 years of GnRHa treatment in addition to $\mathrm{GH}$ treatment during childhood does not have an adverse effect on body composition at the age of 21 years. This strengthens the hypothesis that the previously reported adverse effect on body composition in patients with CPP could be due to the natural course of body composition after CPP rather than due to GnRHa treatment.

Our findings show that changes in SBP and DBP during 5 years after cessation of $\mathrm{GH}$ were similar in the GnRHa/GH and GH groups. Also, the GnRHa/ GH-treated young adults had a similar SBP and DBP as healthy young adults born AGA. High blood pressure was only present in 3 participants of the GnRHa/ GH group, which was similar in the GH-only and AGA groups. Two case reports have described transient arterial hypertension during GnRHa treatment $(31,32)$. Both cases showed that blood pressure returned to normal values after cessation of GnRHa treatment. In our study, none of the participants had to cease their GnRHa treatment because of high arterial blood pressure. Our results show that in the GnRHa/GH group, both SBP and DBP remain well within the normal range and are similar to the GH group and young adults born AGA.

Serum lipid levels changed similarly in the GnRHa/ $\mathrm{GH}$ and $\mathrm{GH}$ groups during 5 years after GH cessation. At 21 years of age, the GnRHa/GH-treated young adults had similar serum TC, HDLc, LDLc, and TG levels as the GH-treated young adults born SGA and the healthy young adults born AGA. This is in line with other studies performed during GnRHa treatment in children with CPP, reporting no changes in lipid levels $(6,33)$. Our results in young adults show that serum lipid levels are not different due to 2 years of GnRHa treatment during childhood.

We have previously reported that the control group of young adults born SGA treated with GH-only had a similar metabolic health profile as untreated young adults born SGA $(34,35)$. As the results in the present study are similar between the $\mathrm{GnRHa} / \mathrm{GH}$ and $\mathrm{GH}$ groups, it is likely that metabolic health after 2 additional years of GnRHa treatment to GH treatment is also similar to untreated young adults born SGA.

During 5 years after $\mathrm{GH}$ cessation, $\mathrm{BMD}_{\mathrm{TB}}$ and $\mathrm{BMAD}_{\mathrm{LS}}$ changed similarly in the $\mathrm{GnRHa} / \mathrm{GH}$ and $\mathrm{GH}$ groups, and both groups had a similar $\mathrm{BMD}_{\mathrm{TB}}$ and $\mathrm{BMAD}_{\mathrm{LS}}$ at 5 years after $\mathrm{GH}$ cessation. This is in line with studies in participants with CPP, describing a similar BMD at $\mathrm{AH}$ in GnRHa-treated participants and participant controls $(9,19,36,37)$. Our findings show that 2 years of GnRHa treatment in addition to $\mathrm{GH}$ treatment has no negative effects on BMD in young adults born SGA.

In conclusion, our longitudinal follow-up study in young adults born SGA during the 5 years after GH cessation shows that the changes in insulin sensitivity, $\beta$ cell function, body composition, blood pressure, serum 
lipid levels, and BMD were unaffected by the addition of 2 years of GnRHa treatment for postponement of puberty. At 21 years of age, insulin sensitivity, $\beta$-cell function, body composition, blood pressure, serum lipid levels, and BMD were similar in GnRHa/GH-treated participants compared with GH-treated young adults born SGA and untreated young adults born AGA. These results show that the addition of 2 years of GnRHa treatment to long-term GH treatment of children short in stature born SGA does not have an unfavorable effect on metabolic health and bone mineralization at the age of 21 years.

\section{Acknowledgments}

We express our gratitude to all children and their parents who participated in this study. We thank J. Bontenbal-van de Wege, C. Bruinings-Vroombout, N. Khieroe, and E. Lems, research nurses, for their contribution to the study; all the collaborating paediatric-endocrinologists of the Dutch Advisory Group on GH Therapy; and the paediatricians who referred patients to participate in this study. We acknowledge the investigator-initiated independent research grants provided by Novo Nordisk BV and Pfizer BV, The Netherlands. The PROGRAM/PREMS study was financially supported by the Netherlands Organisation for Scientific Research (ACSH-K received the ASPASIA-award, grant number 015000 088).

Financial Support: Novo Nordisk and Pfizer, The Netherlands.

Author Contributions: A.C.S.H.-.K was the principal investigator, had the idea for and designed the study, contributed to data collection and interpretation, and wrote the report. W.J.G. collected, analyzed, and interpreted data, wrote the report, and designed the figures. G.F.K. and M.v.d.S. collected and interpreted data and critically reviewed the report.

\section{Additional Information}

Correspondence: Wesley J. Goedegebuure, Department of Paediatrics, Subdivision Endocrinology, Erasmus University Medical Centre, Rotterdam, Dr Molewaterplein 40, 3015 GJ Rotterdam. E-mail: w.goedegebuure@erasmusmc.nl.

Disclosure Summary: Investigator-initiated study for which A.C.S.H.-K. received an independent research grant by Novo Nordisk and Pfizer Netherlands.

\section{References}

1. Sas T, de Waal W, Mulder P, et al. Growth hormone treatment in children with short stature born small for gestational age: 5-year results of a randomized, double-blind, dose-response trial. J Clin Endocrinol Metab. 1999;84(9):3064-3070.

2. Dahlgren J, Wikland KA; Swedish Study Group for Growth Hormone Treatment. Final height in short children born small for gestational age treated with growth hormone. Pediatr Res. 2005;57(2):216-222.
3. Van Pareren Y,Mulder P,Houdijk M, Jansen M, Reeser M, HokkenKoelega A. Adult height after long-term, continuous growth hormone $(\mathrm{GH})$ treatment in short children born small for gestational age: results of a randomized, double-blind, dose-response GH trial. J Clin Endocrinol Metab. 2003;88(8):3584-3590.

4. Lem AJ, van der Kaay DC, de Ridder MA, et al. Adult height in short children born SGA treated with growth hormone and gonadotropin releasing hormone analog: results of a randomized, dose-response GH trial. J Clin Endocrinol Metab. 2012;97(11):4096-4105.

5. Chiavaroli V, Liberati M, D'Antonio F, et al. GNRH analog therapy in girls with early puberty is associated with the achievement of predicted final height but also with increased risk of polycystic ovary syndrome. Eur J Endocrinol. 2010;163(1):55-62.

6. Sørensen K, Mouritsen A, Mogensen SS, Aksglaede L, Juul A. Insulin sensitivity and lipid profiles in girls with central precocious puberty before and during gonadal suppression. J Clin Endocrinol Metab. 2010;95(8):3736-3744.

7. Taşcilar ME, Bilir P, Akinci A, et al. The effect of gonadotropinreleasing hormone analog treatment (leuprolide) on body fat distribution in idiopathic central precocious puberty. Turk J Pediatr. 2011;53(1):27-33.

8. Faienza MF, Brunetti G, Acquafredda A, et al. Metabolic outcomes, bone health, and risk of polycystic ovary syndrome in girls with idiopathic central precocious puberty treated with gonadotropin-releasing hormone analogues. Horm Res Paediatr. 2017;87(3):162-169.

9. Magiakou MA, Manousaki D, Papadaki M, et al. The efficacy and safety of gonadotropin-releasing hormone analog treatment in childhood and adolescence: a single center, long-term follow-up study. J Clin Endocrinol Metab. 2010;95(1):109-117.

10. Lazar L, Lebenthal Y, Yackobovitch-Gavan M, et al. Treated and untreated women with idiopathic precocious puberty: BMI evolution, metabolic outcome, and general health between third and fifth decades. J Clin Endocrinol Metab. 2015;100(4):1445-1451.

11. Aguiar AL, Couto-Silva AC, Vicente EJ, Freitas IC, Cruz T, Adan L. Weight evolution in girls treated for idiopathic central precocious puberty with GnRH analogues. J Pediatr Endocrinol Metab. 2006;19(11):1327-1334.

12. van der Sluis IM, Boot AM, Krenning EP, Drop SL, de Muinck Keizer-Schrama SM. Longitudinal follow-up of bone density and body composition in children with precocious or early puberty before, during and after cessation of $\mathrm{GnRH}$ agonist therapy. J Clin Endocrinol Metab. 2002;87(2):506-512.

13. Park HK, Lee HS, Ko JH, Hwang IT, Lim JS, Hwang JS. The effect of gonadotrophin-releasing hormone agonist treatment over 3 years on bone mineral density and body composition in girls with central precocious puberty. Clin Endocrinol (Oxf). 2012;77(5):743-748.

14. Boot AM, De Muinck Keizer-Schrama S, Pols HA, Krenning EP, Drop SL. Bone mineral density and body composition before and during treatment with gonadotropin-releasing hormone agonist in children with central precocious and early puberty. J Clin Endocrinol Metab. 1998;83(2):370-373.

15. Saggese G, Bertelloni S, Baroncelli GI, Battini R, Franchi G. Reduction of bone density: an effect of gonadotropin releasing hormone analogue treatment in central precocious puberty. Eur J Pediatr. 1993;152(9):717-720.

16. Antoniazzi F, Bertoldo F, Zamboni G, et al. Bone mineral metabolism in girls with precocious puberty during gonadotrophinreleasing hormone agonist treatment. Eur J Endocrinol. 1995;133(4):412-417.

17. van der Steen M, Lem AJ, van der Kaay DC, et al. Metabolic health in short children born small for gestational age treated with growth hormone and gonadotropin-releasing hormone analog: results of a randomized, dose-response trial. J Clin Endocrinol Metab. 2015;100(10):3725-3734. 
18. van der Steen M, Lem AJ, van der Kaay DC, Hokken-Koelega AC. Insulin sensitivity and $\beta$-cell function in SGA children treated with $\mathrm{GH}$ and GnRHa: results of a long-term trial. J Clin Endocrinol Metab. 2016;101(2):705-713.

19. Lem AJ, van der Kaay DC, Hokken-Koelega AC. Bone mineral density and body composition in short children born SGA during growth hormone and gonadotropin releasing hormone analog treatment. J Clin Endocrinol Metab. 2013;98(1):77-86.

20. Fredriks AM, van Buuren S, Burgmeijer RJ, et al. Continuing positive secular growth change in The Netherlands 1955-1997. Pediatr Res. 2000;47:316-323.

21. Kerkhof GF, Breukhoven PE, Leunissen RW, Willemsen RH, Hokken-Koelega AC. Does preterm birth influence cardiovascular risk in early adulthood? J Pediatr. 2012;161:390-396.e391.

22. Leunissen RW, Kerkhof GF, Stijnen T, Hokken-Koelega A. Timing and tempo of first-year rapid growth in relation to cardiovascular and metabolic risk profile in early adulthood. JAMA. 2009;301(21):2234-2242.

23. Johnson J, Dawson-Hughes B. Precision and stability of dualenergy $\mathrm{x}$-ray absorptiometry measurements. Calcif Tissue Int. 1991;49(3):174-178.

24. Guo Y, Franks PW, Brookshire T, Antonio Tataranni P. The intraand inter-instrument reliability of DXA based on ex vivo soft tissue measurements. Obes Res. 2004;12(12):1925-1929.

25. Kröger H, Vainio P, Nieminen J, Kotaniemi A. Comparison of different models for interpreting bone mineral density measurements using DXA and MRI technology. Bone. 1995;17(2):157-159.

26. Boot AM, Bouquet J, de Ridder MA, Krenning EP, de Muinck Keizer-Schrama SM. Determinants of body composition measured by dual-energy x-ray absorptiometry in Dutch children and adolescents. Am J Clin Nutr. 1997;66(2):232-238.

27. van der Sluis IM, de Ridder MA, Boot AM, Krenning EP, de Muinck Keizer-Schrama SM. Reference data for bone density and body composition measured with dual energy $\mathrm{x}$ ray absorptiometry in white children and young adults. Arch Dis Child. 2002;87(4):341-347; discussion 341.

28. Rosner B, Prineas RJ, Loggie JM, Daniels SR. Blood pressure nomograms for children and adolescents, by height, sex, and age, in the United States. J Pediatr. 1993;123(6):871-886.
29. Chiocca E, Dati E, Baroncelli GI, et al. Body mass index and body composition in adolescents treated with gonadotropinreleasing hormone analogue triptorelin depot for central precocious puberty: data at near final height. Neuroendocrinology. 2009;89(4):441-447.

30. Prentice P, Viner RM. Pubertal timing and adult obesity and cardiometabolic risk in women and men: a systematic review and meta-analysis. Int J Obes (Lond). 2013;37(8):1036-1043.

31. Sifaki L, Cachat F, Theintz G, Chehade H. Transient arterial hypertension induced by gonadotropin-releasing hormone agonist treatment for central precocious puberty. Front Pediatr. 2019;7:74

32. Palma L, Gaudino R, Cavarzere P, Antoniazzi F. Does the risk of arterial hypertension increase in the course of triptorelin treatment? J Pediatr Endocrinol Metab. 2020;33(3):449-452.

33. Arcari AJ, Freire AV, Escobar ME, et al. One-year treatment with gonadotropin-releasing hormone analogues does not affect body mass index, insulin sensitivity or lipid profile in girls with central precocious puberty. J Pediatr Endocrinol Metab. 2019;32(2):181-186.

34. van der Steen M, Kerkhof GF, Smeets CCJ, Hokken-Koelega ACS. Cardiovascular risk factors and carotid intima media thickness in young adults born small for gestational age after cessation of growth hormone treatment: a 5-year longitudinal study. Lancet Diabetes Endocrinol. 2017;5(12):975-985.

35. van der Steen M, Smeets CC, Kerkhof GF, Hokken-Koelega AC. Metabolic health of young adults who were born small for gestational age and treated with growth hormone, after cessation of growth hormone treatment: a 5-year longitudinal study. Lancet Diabetes Endocrinol. 2017;5(2):106-116.

36. Alessandri SB, Pereira Fde A, Villela RA, et al. Bone mineral density and body composition in girls with idiopathic central precocious puberty before and after treatment with a gonadotropin-releasing hormone agonist. Clinics (Sao Paulo). 2012;67(6):591-596.

37. Heger S, Partsch CJ, Sippell WG. Long-term outcome after depot gonadotropin-releasing hormone agonist treatment of central precocious puberty: final height, body proportions, body composition, bone mineral density, and reproductive function. J Clin Endocrinol Metab. 1999;84(12):4583-4590. 